group. The prognostic implications of subclinical CMR findings remain unclear and would benefit from longer follow-up.

Abstract AB0653 Table 1. CMR measures in SSc patients with CV events versus SSc patients with no CV events

\begin{tabular}{|c|c|c|c|}
\hline CMR variable & $\begin{array}{c}\text { SSc patients with CV } \\
\text { events } n=12 \\
\text { Mean (SD) }\end{array}$ & $\begin{array}{c}\text { SSc patients with no CV } \\
\text { events, } n=61 \\
\text { Mean (SD) }\end{array}$ & $\begin{array}{c}p \\
\text { value }\end{array}$ \\
\hline $\begin{array}{l}\text { LVEDV/BSA (ml/ } \\
\left.\mathrm{m}^{2}\right)\end{array}$ & $83(17)$ & $76(15)$ & 0.158 \\
\hline $\begin{array}{l}\text { LVESV/BSA (ml/ } \\
\left.\mathrm{m}^{2}\right)\end{array}$ & $33(12)$ & $30(9)$ & 0.222 \\
\hline $\begin{array}{l}\text { LVSV/BSA (ml/ } \\
\left.\mathrm{m}^{2}\right)\end{array}$ & $50(7)$ & $47(7)$ & 0.259 \\
\hline $\begin{array}{l}\text { LV mass/BSA }(\mathrm{g} / \\
\left.\mathrm{m}^{2}\right)\end{array}$ & $49(10)$ & $43(11)$ & $0.043^{*}$ \\
\hline LVEF\% & $61(7)$ & $62(5)$ & 0.494 \\
\hline ECV\% & 31(2) & $30(4)$ & 0.572 \\
\hline T1 native(ms) & $1210(78)$ & $1238(72)$ & 0.262 \\
\hline $\begin{array}{l}\text { LGE, n Scar } \\
\text { mass }\end{array}$ & $10.80(1.68)$ & $90.41(1.14)$ & $\begin{array}{c}0.678 \\
\left(X^{2}\right. \\
\text { test }) \\
0.359\end{array}$ \\
\hline MPR & $1.8(0.5)$ & $2.2(0.8)$ & 0.375 \\
\hline
\end{tabular}

Disclosure of Interests: Raluca-Bianca Dumitru: None declared, Lesley Anne Bissell: None declared, Bara Erhayiem: None declared, Graham Fent : None declared, Ananth Kidambi : None declared, Peter Swoboda: None declared, Helena Donica: None declared, Agata Burska : None declared, John Biglands : None declared, John Greenwood: None declared, Francesco Del Galdo: None declared, Sven Plein : None declared, Maya Buch Grant/research support from: Pfizer LTD, UCB, Consultant for: AbbVie, Eli Lilly, EMD Serono, Pfizer Ltd., Sanofi DOI: 10.1136/annrheumdis-2019-eular.4528

\section{AB0654 NAILFOLD MICROVASCULAR CHANGES IN MIXED CONNECTIVE TISSUE DISEASE: DIFFERENCES WITH SYSTEMIC SCLEROSIS}

Alberto Sulli ${ }^{1}$, Giorgia Ferrari ${ }^{1}$, Carmen Pizzorni ${ }^{1}$, Sabrina Paolino ${ }^{1}$ Vanessa Smith ${ }^{2,3,4}$, Elisa Alessandri ${ }^{1}$, Massimo Patanè ${ }^{1}$, Maurizio Cutolo ${ }^{1}$ ${ }^{1}$ Research Laboratory and Academic Division of Clinical Rheumatology, Department of Internal Medicine, IRCCS Polyclinic Hospital San Martino, University of Genoa, Genoa, Italy; ${ }^{2}$ Department of Rheumatology, Ghent University Hospital, Ghent, Belgium; ${ }^{3}$ Department of Internal Medicine, Ghent University, Ghent, Belgium; ${ }^{4}$ Unit for Molecular Immunology and Inflammation, VIB Inflammation Research Center (IRC), Ghent, Belgium

Background: Detailed nailfold capillary abnormalities have not been described in mixed connective tissue disease (MCTD) as well as their changes over time, unlike systemic sclerosis (SSc) which microvascular damage has been classified and validated by nailfold videocapillaroscopy (NVC) in specific and progressive scleroderma patterns ("Early", "Active", "Late") (1-5).

Objectives: Aim of this study was to retrospectively compare detailed MCTD nailfold capillary abnormalities with those of SSc patients at first visit, and to monitor MCTD capillary changes over time.

Methods: Ten patients (mean disease duration $6.4 \pm 4.2$ years, mean age $50 \pm 19$ years,) affected by MCTD (Kasukawa's criteria) were enrolled Patients with either anti-extractable nuclear antigen positivity different from U1RNP or anti-dsDNA antibodies were excluded. Main capillary parameters (scores of enlarged capillaries, giant capillaries, microhemorrhages, capillary ramifications, as well as absolute number of normal and total capillaries per linear millimetre) were assessed in MCTD patients at their first NVC analysis (TO), and during a three year follow-up. Furthermore NVC parameters were compared at T0 with 10 random SSc patients matched for disease duration ( $6.4 \pm 4.2$ years) and age ( $51 \pm 17$ years) Statistical analysis was performed by non parametric tests.

Results: The capillaroscopic scores of enlarged capillaries, giant capillaries and microhemorrhages were found significantly higher in SSc versus MCTD patients at T0 $(2.50 \pm 0.5$ vs $1.90 \pm 0.6 \mathrm{p}=0.04,1.63 \pm 0.7$ vs $0.70 \pm 0.7$ $p<0.02,1.25 \pm 0.7$ vs $0.70 \pm 0.7 p=0.05$, respectively). Moreover, the absolute number of both total capillaries and normal capillaries were found significantly lower in SSc versus MCTD patients $(5.8 \pm 1.9$ vs $7.6 \pm 1.6$ $\mathrm{p}=0.04$ and $0.45 \pm 1.0$ vs $3.03 \pm 2.9 \mathrm{p}=0.009$ ). On the contrary, no statistically significant difference was observed at T0 for the other capillary parameters (including capillary ramifications) between the two groups of patients. With the limit of a different pharmacological background among patients, no statistically significant variation of the scores, as well as of the absolute value of the above reported capillary parameters was observed during the 3 years of follow-up in MCTD patients. No statistically significant correlation was observed between capillary parameters and MCTD clinical aspects (Raynaud phenomenon, dysphagia, dyspnoea sclerodactily, sicca syndrome, teleangectasias and artharlgia) at first visit and during follow-up.

Conclusion: In a limited cohort of MCTD patients with an average disease duration of 6.4 years and a follow-up of three years, the nailfold microvascular damage does not seem to be significantly progressive. Patients with MCTD seem to show less enlarged/giant capillaries, and larger absolute number of total and normal capillaries than SSc patients.

\section{REFERENCES}

[1] De Holanda Mafaldo DA, et al. Lupus. 2007; 16:254-8.

2.. Cappelli S, et al. Semin Arthritis Rheum. 2012; 41:589-98.

[3] .Cutolo

M. et al. Best Pract Res Clin Rheumatol 2008; 22:1093-108.

[4] .Cutolo M. et al. J Rheumatol. 2000; 27:155-60.

[5] Sulli A, et al. Arthritis Rheum. 2012;64:821-5.

Disclosure of Interests: None declared

DOI: 10.1136/annrheumdis-2019-eular.6946

\section{AB0655 SCLERONET ${ }^{\circledR}:$ A PATIENT-CENTERED MULTIDISCIPLINARY APPROACH TO SYSTEMIC SCLEROSIS}

Ilaria Galetti, Lauretta Bonini. GILS - Gruppo Italiano Lotta alla Sclerodermia, Milan, Italy

Background: Systemic Sclerosis (SSc) is a rare connective tissue disease which may affect almost the whole body ${ }^{1}$. Because of its clinical complexity and heterogeneity, a multidisciplinary approach is helpful to patients.

Objectives: The project aims at providing evidence that a multidisciplinary approach allows to early detect and rightly treat diseases linked to SSc determining an improvement of the Quality of Life (QoL) for patients.

Methods: GILS, the Italian SSc Patient Organisation, selected 4 expert centers in Milan (where over one thousand patients are treated), among those able to diagnose and cure SSc in its different and difficult aspects Inside these hospitals excellences have been identified: immuno-rheumatologists (overall management of SSc), cardiologists (cardio-pulmonary involvement and Pulmonary Arterial Hypertension - $\mathrm{PAH}$ ), maxillofacia and plastic surgeons (lipofilling), odontologists (difficult dental cure due to microstomia), dermatologists (prevention of skin cancer), ophthalmologists (dryness of the eye), vasculars (digital ulcers - DUs), pneumologists (lung fibrosis), gynaecologists (dryness of the vagina) and nutritionists (malabsorption). Specialists can share, care and cure inside this net. A monthly meeting is held with patient representatives (PRs). No private data are disclosed. Hospitals General and Sanitary Managers must give a positive evaluation every year in order to continue ScleroNet ${ }^{\circledR}$ project.

Results: The monthly meeting allows to understand strength and threads and find the way to improve ScleroNet ${ }^{\circledR}$. The PRs point out the unmet needs ${ }^{2}$, to keep ScleroNet ${ }^{\circledR}$ patient-centered and to focus the attention on the QoL whose improvement has been described by patients but not yet supported for all interventions by questionnaires.

Common inclusion and exclusion criteria have been established.

Cardiologists performed 110 assessments through EKG, echocardiography and cardiopulmonary exercise testing. These tests gave the following diagnosis: 16 non-ischemic cardiomyopathy (after BNP and troponin dosage as well as cardiac MRI) got an immunosuppressive therapy; 22 PAHs; 34 diastolyc disfunctions; 23 respiratory disease. The rest did not receive a specific diagnosis but still in follow up.

70 perioral lipofillings have been carried out: body weight rose by 2 to 3 $\mathrm{kg}$ after 4 months in patients with low BMI thanks to a greater mouth opening. Moreover, a better elasticity of the perioral area led to better oral hygiene, speech and self-perception

115 patients before Anti-TNF therapy have been screened to prevent non-melanoma skin cancer; 6 the diagnosis.

10 lipofillings for DUs nonresponsive to pharmacological therapy.

UCLA/MUST questionnaires were given to selected patients in order to evaluate the $\mathrm{Gl}$ involvement and undergo a nutritionist evaluation.

A non-rheumatologist made his first SSc diagnosis due to the personal increased knowledge.

Conclusion: ScleroNet ${ }^{\circledR}$ provides a fruitful practical support to patients in order to receive the best care and cure inside the experts centers in a 
delimited area, according to their specific problems. ScleroNet ${ }^{\circledR}$ seems to enable the experts to networking specifically on SSc, giving the opportunity of sharing their knowledge. Without ScleroNet ${ }^{\circledR}$ the timing of treatment and/or diagnosis would have been delayed. Nevertheless, due to the fact that it is a work-in-progress and some experts have been enrolled in a second stage, data are available only for some interventions. The use of validated questionnaires and indicators are necessary to measure and prove the value of ScleroNet ${ }^{\circledR}$.

\section{REFERENCES}

[1] - Kowal-Bielecka O, Fransen J, Avouac J EUSTAR Coauthors, et al Update of EULAR recommendations for the treatment of systemic sclerosis Annals of the Rheumatic Diseases 2017:76:1327-1339.

2. - Smith V, Scirè CA, Talarico R, et al Systemic sclerosis: state of the art on clinical practice guidelines RMD Open 2019;4:e000782. doi: 10.1136/ rmdopen-2018-000782

Disclosure of Interests: None declared

DOI: 10.1136/annrheumdis-2019-eular.7238

\section{AB0656 ANTISYNTHETASE SYNDROME: CLINICAL VALUE OF SOLOMON'S AND CONNORS' DIAGNOSIS CRITERIA}

Martín Greco ${ }^{1}$, María Jesús García de Yébenes ${ }^{2}$, Inmaculada Alarcón ${ }^{1}$, Anahy Brandy-Garcia ${ }^{3,4}$, Iñigo Rua-Figueroa ${ }^{1}$, Estíbaliz Loza ${ }^{2}$, Teresa Oton ${ }^{2}$, Juan Carlos Quevedo-Abeledo ${ }^{1}$, Carlos Rodriguez-Lozano ${ }^{1}$, Loreto Carmona ${ }^{2} .{ }^{1}$ Hospital Universitario de Gran Canaria Dr. Negrín., Las Palmas, Spain; ${ }^{2}$ Instituto de Salud Musculoesquelética, Madrid, Spain; ${ }^{3}$ Hospital Universitari Germans Trias i Pujol, Barcelona, Spain: ${ }^{4}$ Hospital Universitario Central de Asturias, Oviedo, Spain

Background: Two antisynthetase syndrome (ASSD) diagnosis criteria sets have been proposed; both consider mandatory the presence of anti-aminoacyl transfer RNA synthetase (ARS) autoantibodies. Solomon's criteria consider major clinical criterions (interstitial lung disease (ILD) and fulfillment of Bohan and Peter criteria for DM/PM) and minor criterions (arthritis, Raynaud's phenomenon (RP) and mechanic's hands (MH)) (1). In contrast, Connors criteria evaluate the presence of at least one of the previously mentioned clinical features except myositis, and includes the presence of fever without other cause (2).

Objectives: 1) To evaluate the performance of Solomon's and Connors criteria in patients with clinical suspicion of ASSD or myositis and positive ARS. 2) To describe their clinical characteristics.

Methods: We performed an observational retrospective study in two centers. All patients with clinical suspicion of ASSD or myositis, and positive ARS in the myositis immunoblot (Euroimmun assay) were included.

Results: We analyzed 37 patients; $70.3 \%$ woman, with a mean age at the moment of the ARS detection of $51.4(S D \pm 14.0)$ years, median time from the first symptom to the ARS detection of $4.0(\mathrm{SD} \pm 5.8)$ years, and time of evolution of $7.69(\mathrm{SD} \pm 6.51)$ years. The frequency of ARS was: anti-Jo1 $(n=17)$, anti-PL-12 $(n=8)$, anti-PL-7 $(n=4)$, anti-EJ $(n=4)$, and antiOJ $(n=4)$.

Diagnosis criteria fulfillment and clinical manifestations:

1) Patients that met Solomon and Connors' criteria ( $n=17,45.9 \%)$ :

At disease onset: ILD $(n=6,35.9 \%)$, muscle weakness (MW) $(n=5$, $29.4 \%)$, and arthritis $(n=4,23.5 \%)$.

During disease development: ILD ( $n=14,82.3 \%)$; arthritis $(n=13,76.5 \%)$; MW $(n=10,58.8 \%)$; mechanic hands $(n=10,58.8 \%)$; Raynaud phenomenon $(n=8,47.0 \%)$; and fever $(n=3,17.5 \%)$

2) Patients that only met Connors' criteria ( $n=17,45.9 \%)$ :

- At disease onset: ILD $(n=5,29.4 \%), \quad M W(n=3,17.6 \%)$, or arthritis $(n=5,29.4 \%)$.

- During disease development: Arthritis ( $n=8,47.0 \%)$; ILD ( $n=6,35.3 \%)$; MW ( $n=6,35.3 \%)$; Raynaud phenomenon $(n=6,35.3 \%)$; fever $(n=5$, $29.4 \%)$; and mechanic hands $(n=1,5.9 \%)$

Relative risk (RR) of the different clinical manifestation for Solomon's criteria fulfillment:

$\mathrm{MH} \quad \mathrm{RR}=2.98(95 \% \mathrm{Cl}$ 1.5-5.6; $\mathrm{P}=0.002), \quad$ ILD $\quad \mathrm{RR}=3.2 \quad(95 \% \mathrm{Cl}$ 1.1-9.2; $\mathrm{P}=0.013)$; other manifestations does not presented significant RR.

Conclusion: More than three quarter of all patients presented as first clinical manifestation one of those included in the ASSD classic triad (ILD, MW and arthritis). These manifestations showed increasing rates during the disease development, being more frequent in patients that met Solomon's criteria than in those who only met Connor's criteria; more than twice as high in for ILD, and almost twice for MW and arthritis. This suggests that patients who met Solomon's criteria, at disease onset presented incomplete clinical forms, and their clinical progression favored the criteria fulfillment. On the other hand, we cannot predict if the patients that only met Connors' criteria are going to fulfill Solomon's criteria; nevertheless, our results suggests it.

To conclude, our results suggest that: 1) Connors criteria might be considered for screening of ASSD; 2) Solomon's criteria can be considered at the moment the gold standard for the ASSD diagnosis; 3) the presence of mechanic hands or ILD indicates a high probability of Solomon's criteria fulfillment in patients with positive ARS.

\section{REFERENCES}

[1] Solomon J, et al. Jornal brasileiro de pneumologia. 2011;37(1):100-9.

[2] Connors GR, et al. Chest. 2010;138(6):1464-74.

Disclosure of Interests: Martín Greco: None declared, María Jesús García de Yébenes: None declared, Inmaculada Alarcón: None declared, Anahy Brandy-Garcia: None declared, Iñigo Rua-Figueroa: None declared, Estíbaliz Loza Grant/research support from: Roche, MSD, Pfizer, Abbvie, BMS, UCB, Actelion, Celgene, Grunenthal and Sanofi, Teresa Oton: None declared, Juan Carlos Quevedo-Abeledo: None declared, Carlos Rodriguez-Lozano: None declared, Loreto Carmona Grant/research support from: Abbvie, Actelion, Astellas, BMS, Eisay, Gebro Pharma, Grünenthal, Leo Pharma, Lilly, MSD, Novartis, Pfizer, Roche, Sanofi-Aventis and UCB Pharma, Paid instructor for: Novartis

DOI: 10.1136/annrheumdis-2019-eular.7115

\section{AB0657 ANTISYNTHETASE SYNDROME: NON- ANTISYNTHETASE ANTIBODIES, CLINICAL MANIFESTATIONS AND OVERLAPS}

Martín Greco ${ }^{1}$, María Jesús García de Yébenes ${ }^{2}$, Inmaculada Alarcón ${ }^{1}$, Anahy Brandy-Garcia ${ }^{3,4}$, Iñigo Rua-Figueroa ${ }^{1}$, Estíbaliz Loza ${ }^{2}$, Teresa Oton ${ }^{2}$, R. López-Sánchez ${ }^{1}$, Laur Cáceres Martín ${ }^{1}$, Loreto Carmona ${ }^{2} .{ }^{1}{ }^{H}$ ospital Universitario de Gran Canaria Dr. Negrín., Las Palmas, Spain; ${ }^{2}$ Instituto de Salud Musculoesquelética, Madrid, Spain; ${ }^{3}$ Hospital Universitari Germans Trias i Pujol, Barcelona, Spain; ${ }^{4}$ Hospital Universitario Central de Asturias, Oviedo, Spain

Background: The antisynthetase syndromes (ASSD) are characterized by the presence of anti-aminoacyl transfer RNA synthetase (ARS) autoantibodies and clinical features including myositis, arthritis, interstitial lung disease (ILD), Raynaud's phenomenon (RP), mechanic hands (MH), and fever. Two ASSD diagnosis criteria have been developed; those proposed by Connors, and the stricter criteria proposed by Solomon $(1,2)$. Additionally, other symptoms of connective tissue diseases (CTD) can be present.

Objectives: To describe a series of patients with positive ARS and anaIyze: 1) the associated non-ARS antibodies, 2) the clinical manifestations that are not included in the different ASSD diagnosis criteria; and 3) the initial diagnosis attributed by the Rheumatologist in the clinical records.

Methods: We performed an observational retrospective study in two hospitals. All patients with clinical suspicion of ASSD or myopathy and positive ARS in the myositis immunoblot (Euroimmun assay) were included. Results: We analyzed 37 patients; $70.3 \%$ woman, with a mean age at the moment of the first symptom of $50.5(S D \pm 14.0)$ years, and 51.4 (SD $\pm 14.0)$ years at the moment of the ARS detection. The frequency of ARS was: anti-Jo1 $(n=17)$, anti-PL12 $(n=8)$, anti-PL7 $(n=4)$, anti-EJ $(n=4)$, and anti-OJ $(n=4)$. The rate of the ASSD clinical manifestations was: arthritis $(56.7 \%)$, ILD $(54.1 \%)$, muscle weakness $(48.6 \%)$, RP $(37.8 \%)$, MH $(29.7 \%)$ and fever $(21.6 \%)$. Thirty-four patients $(91.9 \%)$ met Connors' criteria and 17 of them (45.9\%) also met Solomon's criteria.

Non-antisynthetase characteristics:

- Associated non-ARS antibodies: anti-Ro52 ( $n=17,46 \%)$; anti-PM/Scl75 $(\mathrm{n}=6,16.2 \%)$; anti-PM/Scl100 $(\mathrm{n}=5,13.5 \%)$; anticentromere $(\mathrm{n}=3,8.1 \%)$ rheumatoid factor $(n=2,5.4 \%)$; anti-CCP $(n=2,5.4 \%)$; and anti-DNAds $(\mathrm{n}=2,5.4 \%)$. Other antibodies detected only once: Anti-SRP, lupic-anticoagulant, anti-Ku, anti-Mi2, Anticardiolipin, Nor90, Th/To.

- Most frequent clinical manifestations not included in the ASSD diagnosis criteria: dysphagia $(n=10,27 \%)$; dermatomyositis rash $(n=9,24.3 \%)$; and SICCA sympthoms $(n=7,18.9 \%)$.

- First diagnosis attributed by the clinicians in the medical records: ASSD $(n=19,51.35 \%)$, dermatomyositis/polymyositis (DM/PM) $(n=3)$, overlap syndrome $(n=3)$, systemic lupus erythemoatous (SLE) $(n=3)$, primary Sjögren's syndrome (SS) $(n=2)$; rheumatoid arthritis (RA) $(n=2)$; undiferenciated-CTD (UCTD) ( $n=2)$; and Systemic Sclerosis (SSc) $(n=1 ; 2.7 \%)$. Overlaps included 2 DM/PM-SSc and 1 DM/PM-SS, and both UCTD was described with SSc pattern. Thus, of the 18 cases not diagnosed as ASSD, 6 (33.3\%) presented DM/PM diagnosis pattern and 6 (33.3\%) SSc pattern. 